\title{
Impressum, Vol. 17, Supplement 3, 1990
}

Supplement $3 \mathrm{z}^{-} \mathrm{u}$ Band 17, April 1990

Infusionstherapie

Internationale Zeitschrift für Infusionstherapie, klinische Ernährung und Transfusionsmedizin Herausgeber

S. Karger

Verlag für Medizin und Naturwissenschaften $\mathrm{GmbH}$,

Postfach 1724. D-8034 Germeri $\pi$

Presserechtlich verantwortlich: Walter Kunz, Gesellschafter

o

Off $z_{j}$ elles Organ

der Deutschen Arbeitsgeme;nschaft

für künstliche Ernährung (DAKE)

$11 \prod 1 \mathrm{AKE}$

$\wedge^{\wedge} \mathrm{B}^{\wedge} \ddot{\mathrm{A}} \mathrm{B} \Psi \quad$ Ernährung

Off $;$; elles Organ

DÂKI

der Österre ${ }_{j}$ Ch $_{j}$ schen Arbeitsgemejnschaft

für klinische Ernährung (AKE)

Off ${ }_{i} ;$ elles Organ der Deutschen Gesellschaft für Transfusionsmedizin und Immunhämatologie

Gründungsherausgeber

H. Reissigl, w. Hofrat, Innsbruck

Schriftleitung

K.H. Bäßler, Mainz; A. Grünert, Ulm; V. Kretschmer, Marburg; K. Widhalm, Wien

Wissenschaftlicher Beirat

M. Adolph, Augsburg;

F.W. Ahnefeld, Ulm;

K.H. Bäßler, Mainz;

W. Behrendt. Aachen:

H. Bergmann, Linz:

C. Bode. Köln;

P. Deetjen. Innsbruck;

W. Dick, Mainz;

R. Dölp,Fulda;

H. von Domarus, Mainz;

W. Druml, Wien;

J. Eckart, Augsburg;

P. Ferenci, Wien;

H. Förster, Frankfurt;

R. Glaser von Roman, Düsseldorf; 
A. Grünert, Ulm:

J.M. Hackl, Innsbruck;

W. Haider, Wien;

M. Halmágyi. Mainz: W. Hartig. Leipzig; O. Heidenreich, Aachen; U. Henneberg, Berlin;

E. Holm, Mannheim;

G. Kleinberger, Steyr;

K.F. Kopp, München;

V. Kretschmer, Marburg; J. Kult. Bad Mergentheim: H.G. Lasch, Gießen; H. Lochs, Wien: D.

Löhlein, Dortmund; H. Mehnert, München; J.M. Müller. Köln; K. Peter, München;

F. Pohlandt,Ulm;

U. Rabast, Hattingen; H. Reissigl, Innsbruck:

P. Riederer. Würzburg; H. Rossegger, Graz;

E. Roth, Wien;

H.P. Schuster. Hildesheim;

M. Semsroth, Wien;

K. Steinbereithner, Wien;

H.J. Steinhardt, Mainz;

H. Stoeckel, Bonn;

B. Szczygiel, Warschau;

W. Vahlensieck, Bonn;

R. Weiner, Leipzig;

R. Wenger, Wien;

K. Widhalm, Wien;

F. Willig, Heidelberg;

G. Wolfram, München;

R. Zander. Mainz

\section{Anzeigen}

S. Karger Verlag für Medizin und Naturwissenschaften $\mathrm{GmbH}$, Postfach 1724, D-8034 Germering, Telefon (089) 843035.

Gültig ist die Preisliste Nr. 8 vom 1.10.1986.

Für den Inhalt außerhalb des redaktionellen Teiles (insbesondere Anzeigen, Industrieinformationen, Pressezitate und Kongreßinformationen usw.) übernehmen Schriftleitung, Beirat und Verlag keine Gewähr.

Eine Markenbezeichnung kann warenzeichenrechtlich geschützt sein, auch wenn bei ihrer Verwendung in dieser Zeitschrift das Zeichen ${ }^{\circledR}$ oder ein anderer Hinweis auf etwa bestehende Schutzrechte fehlen sollte. Für Satzfehler, insbesondere bei Dosierungsangaben, wird keine Gewähr übernommen.

Alle Rechte, insbesondere das Recht der Vervielfältigung und Mikrokopie sowie der Übersetzung, vorbehalten. Nachdruck, auch auszugsweise, nur mit Genehmigung des Verlages. Fotokopien dürfen nur für den persönlichen Gebrauch als Einzelkopien hergestellt werden. Jede im Bereich eines gewerblichen Unternehmens zulässig hergestellte oder benutzte Kopie dient gewerblichen Zwecken gem. § 54(2) UrhG 
und verpflichtet zur Gebührenzahlung an die Verwertungsgesellschaft WORT, Abt. VG Wissenschaft, Goethestraße 49, D-8000 München 2.

(C) Copyright 1990 by S. Karger, Verlag für Medizin und Naturwissenschaften GmbH, Postfach 1724, D-8034 Germering (BRD)

ISBN 3-8055-5228-9

Satz und Druck: Bonitas-Bauer, Grafischer Betrieb, Max-von-Laue-Straße 31, D-8700 Würzburg Ladenpreis dieses Sonderheftes DM28,-ink1. MwSt.; Abonnenten erhalten es unberechnet.

Bezugspreis der Zeitschrift:

Für Jahrgang 17, 1990, DM 148,-/öS 1036,-/SFr 116,-.

1 Einzelheft kostet DM 28,-/öS 196,-/SFr 22,- einschließlich MwSt. , zuzüglich Postgebühren. KARGER 